\title{
Progress in the Canning Industry in the Last Ten Years
}

\author{
By W. D. Bigelow
}

Director of Regearch Laboratory, National, Canners Association, 1739 H St., N. W., Washington, D. C.

$\mathrm{T}$ HERE are perhaps two distinguishing features of the canning industry of the present decade: First, cooperation of effort, and second, fundamental and systematic study of the principles on which the industry is based.

During this time the idea of trade secrets in technological operations has disappeared from most branches of the canning industry and technological questions are now discussed freely. This policy has resulted in a greatly improved product, and has made it possible to define within broad limits the information of the industry regarding technological processes and to point out more definitely than was heretofore possible the needs of the industry for improvement in those processes.

\section{Raw Products}

It has become evident that canning is intimately connected with agriculture, and that its future success must depend in large manner on the success of growers in producing canning crops. Increased attention has been given to the development of varieties which yield abundantly and, at the

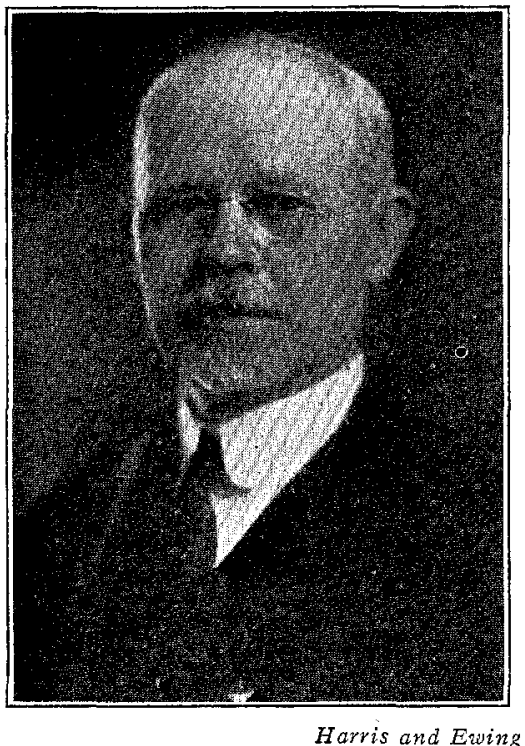

W. D. BIGELOW

\section{Research Laboratory}

As a result of the coöperative spirit already mentioned, the canning industry nine years ago established a research laboratory which might serve as a center for studying the fundamental principles of canning technology. In this laboratory it is possible to study the general problems of the industry more adequately than could be done in a laboratory maintained by a single interest. In addition to general problems, the laboratory receives many complaints and inquiries from individual canners, together with their observations regarding the same. Such communications are often accompanied by samples for inspection or analysis and are frequently followed by experimental work at the canning plant. Collaboration is also received from allied industries, and often with governmental agencies.

\section{Tin Plate and Cans}

During the last ten years we have really begun to understand the desiderata in tin plate intended for packers' cans. We have learned that increasing the weight of coating does not increase the amount of tin dissolved by certain foods, as was same time, possess the characteristics most desired for the production of canned foods. The importance of planting seed that is true to type and which may yield an abundant harvest under satisfactory growing conditions is now generally appreciated.

\section{Canning Machinery}

The last decade has seen the perfection and general use of machines that had been relatively imperfect as well as the development of new machines for operations previously conducted by hand. As a result of the developments in canning machinery, it is now possible to handle many products almost entirely by machine, thus securing greater uniformity, reducing the cost of manufacture, and contributing largely to the sanitation of the canning plants. This improvement in canning machinery is general and applies to nearly all products packed. The following are mentioned merely as illustrations of the progress that has been made in this field:

Corn huskers have come into universal use, and cutters have been so developed that the corn is removed from the cob in a much more satisfactory manner than was formerly possible.

Blanchers have been so developed that they can be used more generally, and many products, such as pumpkins and beets, are now blanched in continuous machines.

Washing machines for preliminary cleansing of all manner of raw products have been brought to a high stage of perfection.

Filling machines for filling the raw product, such as peas and beans, into the cans, have been improved so that the cans may be filled more uniformly and with less mutilation of the product.

Automatic conveyors for the raw product, the empty cans and the filled cans have been highly developed, and greatly facilitale the transportation between different portions of the plant. This improvement in conveyors is advantageous in many ways. It cheapens the cost of production, hastens the operation of canning with a resulting increase in quality, and contributes largely to the general cleanliness of the plant. formerly believed by many to be the case. On the other hand, increasing the weight of coating does materially reduce the number of perforations and consequently the amount of loss experienced with certain fruits. A substantial beginning has also been made in the study of steel intended for the manufacture of tin plate.

During this time the sanitary can has been developed to such an extent that its use with vegetables processed at high temperatures has become practicable. As a result, the sanitary can has practically superseded the old hole-and-cap. can, thus affording a package which not only reduces the cost of operation but enhances the quality of the product.

\section{Processing of Canned Foods}

The characteristic feature of canned foods is that they are placed in hermetically sealed cans and sterilized by heat.

The times and temperatures of processing were entirely a matter of experience, and it was only within the last five years that a systematic study of the fundamentals of processing was inaugurated. This investigation includes: First, the study of the penetration of heat to the center of cans of various kinds of foods; second, the hydrogen-ion concentration of canned foods and the influence of the canning process on the hydrogen-ion concentration of the product; third, the study of the thermal death point of resistant bacteria isolated from spoiled canned foods; and fourth, the correlation of the results of the three separate studies just mentioned and the calculation from the data afforded by those studies of the theoretical time necessary to sterilize various foods at any particular temperature. This theoretical process time is then available for guiding experimental packs of cans of various products inoculated with resistant bacteria. In 